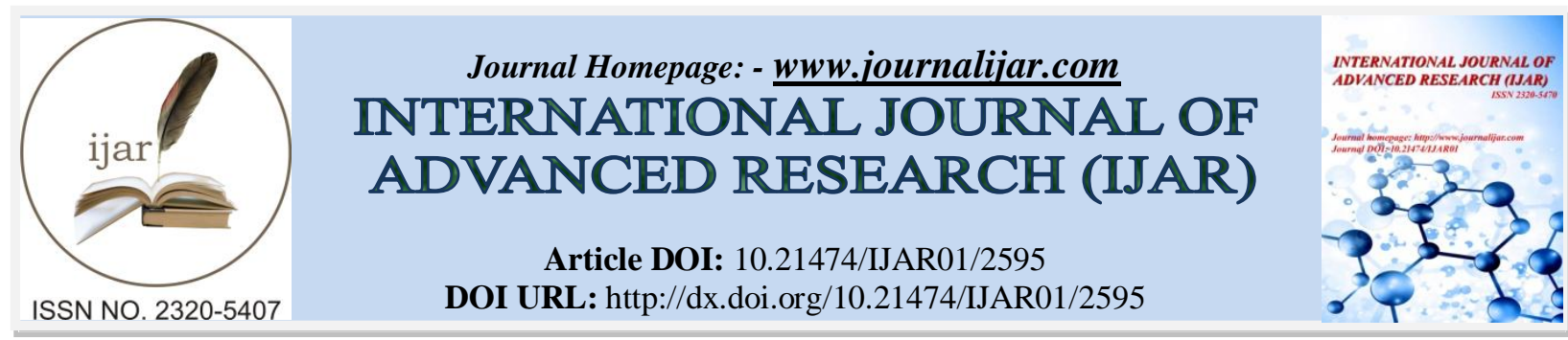

RESEARCH ARTICLE

\title{
A STUDY ON EDUCATIONAL SERVICES OF THE AGHA KHAN UNIVERSITY EXAMINATION BOARD AT SECONDARY SCHOOL LEVEL IN KARACHI, PAKISTAN.
}

\author{
Dr. Rabia A. Karim ${ }^{1}$, Dr. Anila Fatima Shakil ${ }^{1}$ and Dr. Waqar un Nisa ${ }^{2}$. \\ 1. Associate Prof. Jinnah University for Women. \\ 2. Assistant Prof. Shaheed Benazir Bhutto University.
}

\section{Manuscript Info}

Abstract

Manuscript History

Received: 28 October 2016

Final Accepted: 27 November 2016

Published: December 2016

Copy Right, IJAR, 2016,. All rights reserved.

\section{Introduction:-}

Education plays an important role in the development of individual and society. It gives awareness to differentiate between negative and positive aspects of life. It helps to increase the boldness and confidence in people to prove themselves in front of the whole world. In the words of John Dewey, Samuel(2011) is representing the concept of education "Education is the development of all those capacities in the individual which will enable him to control his environment and fulfill his possibilities". Education is something that can groom human personality by polishing inner abilities and gifted talent. Formal education is the chief source to train the new generation according to the requirement of state. It follows certain steps of organized educational system consisting on major four units; objectives, curriculum, teaching methodologies and evaluation. Evaluation is possible by means of specific strategies having chief source of examination in it. In Pakistan we are having secondary board of examination for IX \& X classes while higher secondary board for the assessment of students appearing in XI \& XII standards. But there were so many weaknesses in the traditional set up of our examination boards run by government, so due to these issues there was a parallel new board established in private sector in the era of 2000 known as Aga Khan Examination Board.

\section{Aga Khan Examination Board:-}

Aga khan university examination board is a federal board of intermediate and secondary education established by Aga Khan University in response to demand from schools for more appropriate examination. It was founded in August 2003 in accordance with ordinance CXIV of the government of Pakistan to offer examination services for secondary and higher secondary school certificate throughout Pakistan and abroad. It offers its qualification both in Urdu and English medium. The main objective of AKU-EB is to establish such standardized system of examination which can give worth able position to students with in the country and outside the country for admission at higher level. It also established to improve the standards of learning and teaching at the secondary school level in Pakistan. Its approach is unique in many ways syllabi included SLOs, assessment schemes and teaching strategies.

The major success of the AKU-EB program is having the low cost computerized system of examination at AKU-EB headquarters. It is not only presenting the valid and reliable result reforms but also introducing innovation in educational field.

AKU-EB examination board making information available to the candidates and ask them to bring their ideas and understanding to analyze. AKU-EB as a national board is committed to offer academic qualification for both English and Urdu medium candidates from school across Pakistan. Examination syllabi are designed for each qualification 
to provide the best possible learning support and choice of subjects to the students. AKU-EB is also committed to offer learning opportunities to teachers for their capacity building in the fields of education and assessment. It engages teachers to partaking in various activities such as e -marking material development; item writing invigilation and facilitation of workshops, helping them grow professionally and bring forth their creativity with the enrichment of content as assessment skills.

In a globalize world, nothing is more important than a high quality education system with internationally recognized standards. With a commitment to make more reliable, valid and efferent and secure examination in Pakistan AKUEB is providing its services, using modern methods of assessment to test achievement within the national curriculum of Pakistan so as to have significant impact on quality of education. It is also playing its dynamic role by providing wide range of teaching support materials, enabling them to provide the utmost support to students in class rooms.

\section{Objectives of study:-}

- To identify the number of services provided by the A KU-EB.

- Identify the AKU-EB facilities which are not offered by other boards.

- Assess the quality of AKU-EB's service standards in comparison with other boards.

- Assess the general accessibility of the AKU-EB.

- Identify the number of institutions registered with AKU-EB.

- Assess the satisfaction of client institutions of the AKU-EB.

\section{Review of Related Literature:-}

Aga Khan University Examination Board was established to provide high quality SSC and HSC examination in English and Urdu medium schools. Its major aim is to improve the quality of education. It also arranges training sessions for instructors to develop suitable materials related to students for their better learning. AKU-EB is providing better judgment of student's potential in different areas like; comprehension, intellectual power of thinking and solving issues. By this system of examination we can produce such reliable and competent results which can enable students to take admission in any reputable institute after school with in country or outside.

\section{Objectives of AKU-EB:-}

1. Inculcate a sense of gratitude to almighty Allah for blessing us with an independent and sovereign state.

2. Underscore the importance of national integration, cohesion and patriotism.

3. Encourage traits of observation, creativity, analysis and reflection in students.

4. Promote an understanding of the ideology of Pakistan, the Muslim struggle for independence and endeavors for establishing a modern welfare Islamic state.

5. Highlight Pakistan's strategic position in international politics, especially its relations with neighboring and Muslim countries.

\section{Affiliation of School:-}

It was first time in Pakistan that an examination board was established in private sector. In original ordinance of establishment board was accepted to affiliate schools of private and public sector both.

\section{Acceptability across Pakistan and internationally:-}

AKU-EB's SSC and HSSC certificates are at par with most of the certificates offered by other public boards in Pakistan even abroad. AKU-EB students do not require having an equivalency for their certificates, ensuring increased adaptability and mobility for AKU-EB students within the country.

\section{School Orientation:-}

A complete orientation is presented by the team members /training officers of AKU-EB in one day program to the teachers of affiliated schools. The trainers take help form designed kit and data of orientation of AKU-EB. Almost 69 having around 170 schools have been arranged.

\section{Conducting science practical:-}

An innovative approach has been adopted by AKU for the assessment of student in practical work especially for science subjects. Teachers were therefore invited to attend a daylong workshop on how to conduct practical. 


\section{Governance of AKU-EB:-}

The Board of Directors of AKU-EB constitutes on members from different departments of education like schools, examination boards, and members of HEC.

Reasonable and graded Fee Structure:-

AKU-EB has low fee structure with standardized academic facilitation to all students of various cadre i.e. matriculation as well as $\mathrm{O} \& \mathrm{~A}$ level .

\section{Paper Setting Guidelines:-}

The content for the whole is divided into topics, and the topics are divided into specific learning objectives (SLOs). SLOs are categorized according the cognitive approach i.e. understanding with knowledge. All topics will be examined as per AKU-EB set standards. Beside this the concerned teachers of respective schools are also involved in paper setting process and to be selected as examiners or subject officers to the related subjects/areas. Later on the recruited teachers develop questions and send them to subject specialist/ officer. These are then reviewed and selected on the bases of their difficulty and fit to the model. These questions are received and moderated by chief examiners for further improvement and maintenance of quality education as per related standards.

\section{Printing of Question Papers:-}

Agha Khan University examination board has developed its own learning support site to bring together students and educators from across Pakistan to a common platform where they can find useful resource material, share their expert knowledge and inter change innovative ideas and also play role in printing of question paper. A highly secured method is used for test booklets and presenting the list of selected candidates. Not only this but question papers are also electronically designed and counted by digital printing system. The papers are given digital bar codes for the purpose of e-marking and later on the given data will be linked on separated pages electronically.

\section{E-Marking Team:-}

E-marking is a tool for reliable results of the learners as it is easy to assess exactly where they stand and how much they have learned in their relevant subjects. For this purpose AKU-EB has developed a computerized marking system. The team of qualified and subject expert teachers is selected and among them one will work as a team leader and under her/his six more teachers will company him. All of them will be known as E-markers. The marking will be done by coding system as e-marker examines each answer script randomly. Beside this all e-markers/ examiner have fully equipped to their relevant subjects so the marking will be transparent.

\section{Process of Marking:-}

The answer scripts are scanned by electronic processor and further each script is separated regarding sub questions and items. The hand written separate images will be given to e-markers for screen routing. Along with it for MCQs answers are scored and verified by optical mark reader (OMR). After that electronically sets of data, consisting on both i.e. objective and subjective combine together for further result proceeding. As the whole marking system is done on the basis of blind assessment and specific marking software so it promotes reliability within the results.

\section{E-marking system:-}

AKU-EB has introduced e marking system for transparency in examination process. It has trained teachers by having 35 sessions for chief markers and 164 markers in 16 subjects. It will not enhance the marking skills and techniques for advance examination among teachers but also upgrade marking systems all its affiliated schools as per standardized level.

\section{Result Processing:-}

Online result declaration system is also a reliability of AKU-EB along with its printed certificates, the part of result process. The whole computerized data of student (scanned copy of answer scripts \& results) becomes the part of examination storage.

\section{AKU-EB's Contribution to Feedback:-}

It is also great contribution of AKU-EB that it provides a detailed report of results and achievement of students and also of schools in every subject. Thus it can help schools to improve. In the words of Locke \& Latham 1990; Feedback is one of the most powerful influences on learning and achievement, but this impact can be either positive 
or negative. Feedback allows students to set reasonable goals and track their performance in relation to their goals so that adjustments in efforts, direction and even strategy can be made as needed.

\section{Teaching learning Supportive Program:-}

The AKU_EB mission is to promote respective educational objectives i.e. to train teachers and develop learning materials regarding national curriculum at secondary level and on wards. For this purpose AKU-EB comprehensive teacher development committee is also established.

\section{Needs analysis of Learner:-}

In the words of Weling Kars 2012"A training needs analysis is the process of identifying the areas where both individuals and groups in an organization would benefit for training in order to become more effective at achieving their own objective and the objectives of the organization.

According to Shaw \& Dowsett 1986; It is a necessary component of information retrieval on student's learning needs and should be recorded. Need analysis of student of students is a continuous process as this will help to evaluate and develop the critical thinking, synthesis \& practical approach among students as well as to identify the traditional teachers for training and facilitating better opportunities to them for advancement by AKU-EB.

\section{Strategies for training:-}

AKU-EB has its own training program regarding to the examination, invigilation, preparation and development of materials, planning of lesson and assessment techniques. Beside these AKU also focus on school orientation, paradigm shift of teachers and students in the preparation for examination, classroom teaching and management, teacher training program to its affiliated schools.

\section{Methodology:-}

It is a descriptive research, provides detail information related to the role of AKU-EB in Karachi, Pakistan. The limited population of this study was the teachers and students of affiliated schools of Karachi with AKU-EB. Through questionnaire data was collected by 50 teachers and 50 students of sample. After the collection of data mean, standard deviation and $\mathrm{T}$. test were applied for statistical evaluation.

\section{Results:-}

Data related to teaching method is showing that AKU-EB is working on innovation in teaching, So that affiliated schools are supporting it. Results of mean and SD is showing that majority of teachers and students are appreciating their services in teaching domain. T- test is also emphasized on the such positive role of private sector examination board. The collected data on second domain i.e teacher student involvement is also representing the role of AKUEB. By the results of mean and SD it is clear that under affiliation of AKU-EB teacher and students are involving them more vibrantly. T- test result is demanding the need of such supporting board. Results of mean, SD, and T-test are showing that AKU-EB is working on technical sound basis for the evaluation and assessment process. Unlike the traditional board system examination of Pakistan, its validity and reliability is not doubtful. AKU-EB not only providing its services in the improvement of traditional setup but also working on collecting continuous feedback from affiliated schools. Monitoring is the credibility of AKU-EB, so that schools remain in progressing and developing state due to its functional nature. Statistical analysis of collected data is also proving the same.

\section{Discussion:-}

The traditional system of examination in Pakistan has many weak points in it; constitute on the issues related to paper setting, paper confidentiality, paper conduction and result declaration after stressful long awaiting period. Reliability and validity of results is also in doubt under BISE examination. On the other hand AKU-EB system of examination is designed to avoid all these loose ends of traditional system. Most of the teachers and students during the interviews presented their intention towards this healthy change of examination and appreciating the efforts of AKU-EB in this domain. Such changes and progressive efforts must be shown in all BISE boards throughout the country, as it is not the responsibility of private sector to establish such an advanced system of examination. At government level new system should be launched properly so every school and every student of our country can get benefit. 


\section{Recommendations:-}

- Supervision of the affiliated schools must be done on regular basis, to avoid the misconductions.

- AKU-EB is supposed to be informed students and teachers of affiliated schools about the progress and any kind of change.

- There should be inter-school interactive sessions among the schools affiliated with AKU-EB so that the schools can identify their common issues regarding it.

- AKU-EB must be in constant contact with its affiliated schools, so that the students- teachers' feedback regarding the faced problems in adjusting process can be sort out.

- Teachers of affiliated schools must be given training for prescribed curriculum.

- Government must have to take steps for the improvement of public examination boards on this pattern.

- Training sessions for teachers should be frequently conducted by AKU-EB for better results.

\section{References:-}

1. Shanker Narayan J, Research Methodology, Azad Publisher LHR, 1996.

2. Khan James V, Research in Education, PrinticeHall of India, 2004.

3. Best. W.John, Research in Education, Printice Hall of India, 2004.

4. Kaul Lokesh, Methodology of Education, APH publishers, 2005.

5. Shahid S.M, Introduction of Education, Majid Book Depot, 2000.

6. Ravi Samuel, A Comprehensive study of Education, PHI learning 2011.

7. Shaw \& Dowsett, Need Analysis, 1986.

8. Locke \& Latham A theory of goal setting \& Task performance, Printice Hall,1990

9. www.aku.edu

10. www.examinationboard .aku.edu

11. www.akueb.wordpress.com

12. www.akdn.org/aku

13. www.learning.support.aku.edu.pk

Annex1:-

Statement\# 1:- Teaching Methods:-

\begin{tabular}{|c|c|c|c|c|}
\hline S.No & Items & Mean & SD & Avg T.test \\
\hline 1 & AKU-EB has introduced new teaching methods. & 0.69 & 0.068 & 0.103 \\
2 & AKU-EB gives task to do in groups of students. & 0.7 & 0.069 & 0.103 \\
3 & AKU-EB more focuses on teaching methodologies. & 0.61 & 0.060 & 0.103 \\
4 & AKU-EB asks to study relevant books apart from syllabus & 0.86 & 0.085 & 0.103 \\
& books. & & & \\
\hline
\end{tabular}




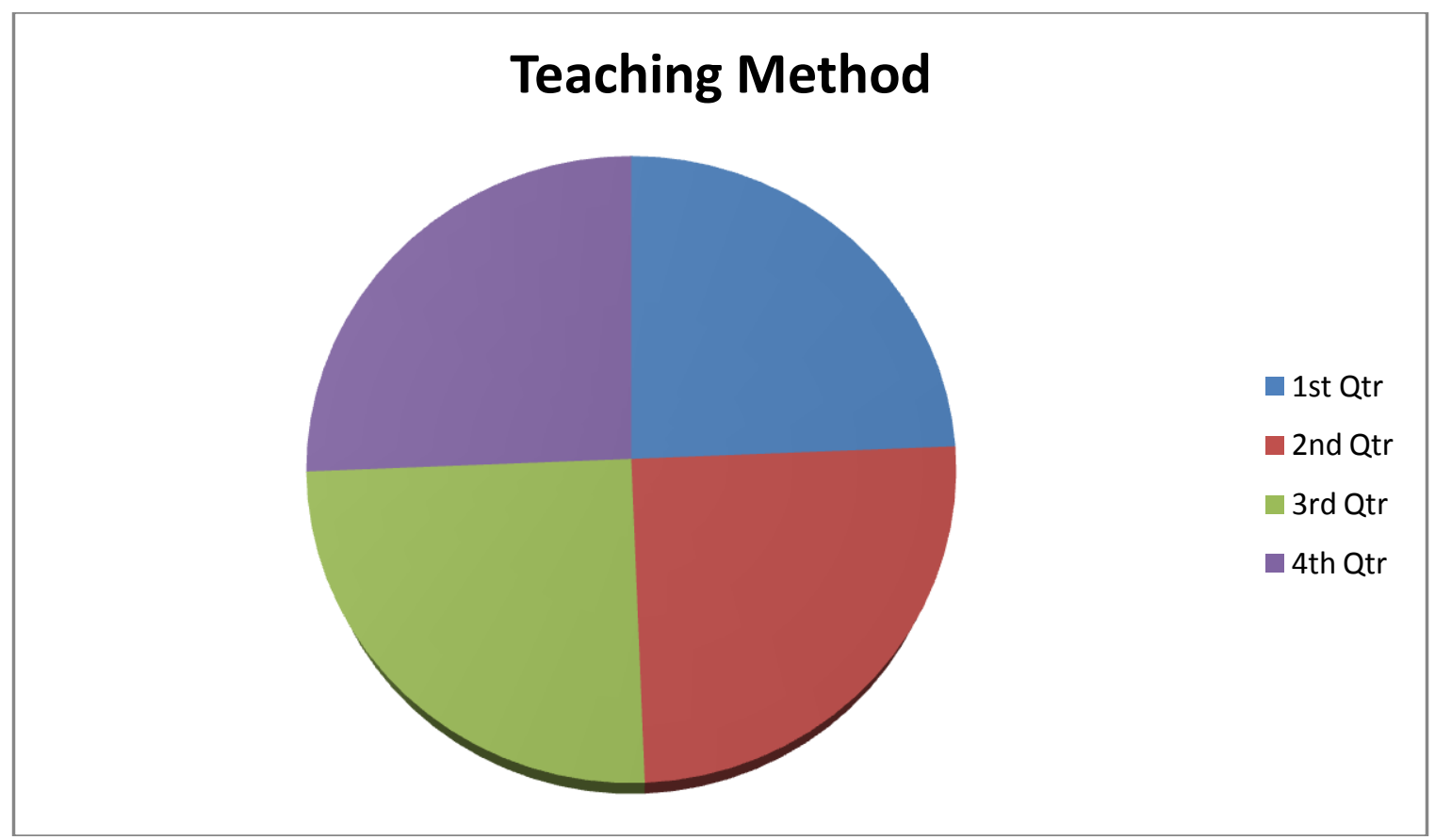

Annex2:-

Statement \#2 Teacher Student Involvement:

\begin{tabular}{|c|c|c|c|c|}
\hline S.No & Items & Mean & SD & Avg T.test \\
\hline 1 & AKU-EB encourages students to participate during & 0.79 & 0.078 & 0.103 \\
& class/lectures & & & \\
2 & AKU-EB welcomes teacher criticism on behalf of students. & 0.56 & 0.037 & 0.103 \\
3 & AKU-EB focuses on student's interactive abilities. & 0.53 & 0.053 & 0.103 \\
4 & AKU-EB curriculum is according to psychological needs of & 0.6 & 0.035 & 0.103 \\
& students & & \\
5 & Curriculum is designed according to the modern techniques & 0.71 & 0.070 & 0.103 \\
& of edu. & & & \\
6 & AKU-EB Curriculum is more effective to the students. & 0.64 & 0.064 & 0.103 \\
7 & Board Provides modern technologies to the students. & 0.59 & 0.059 & 0.103 \\
\hline
\end{tabular}




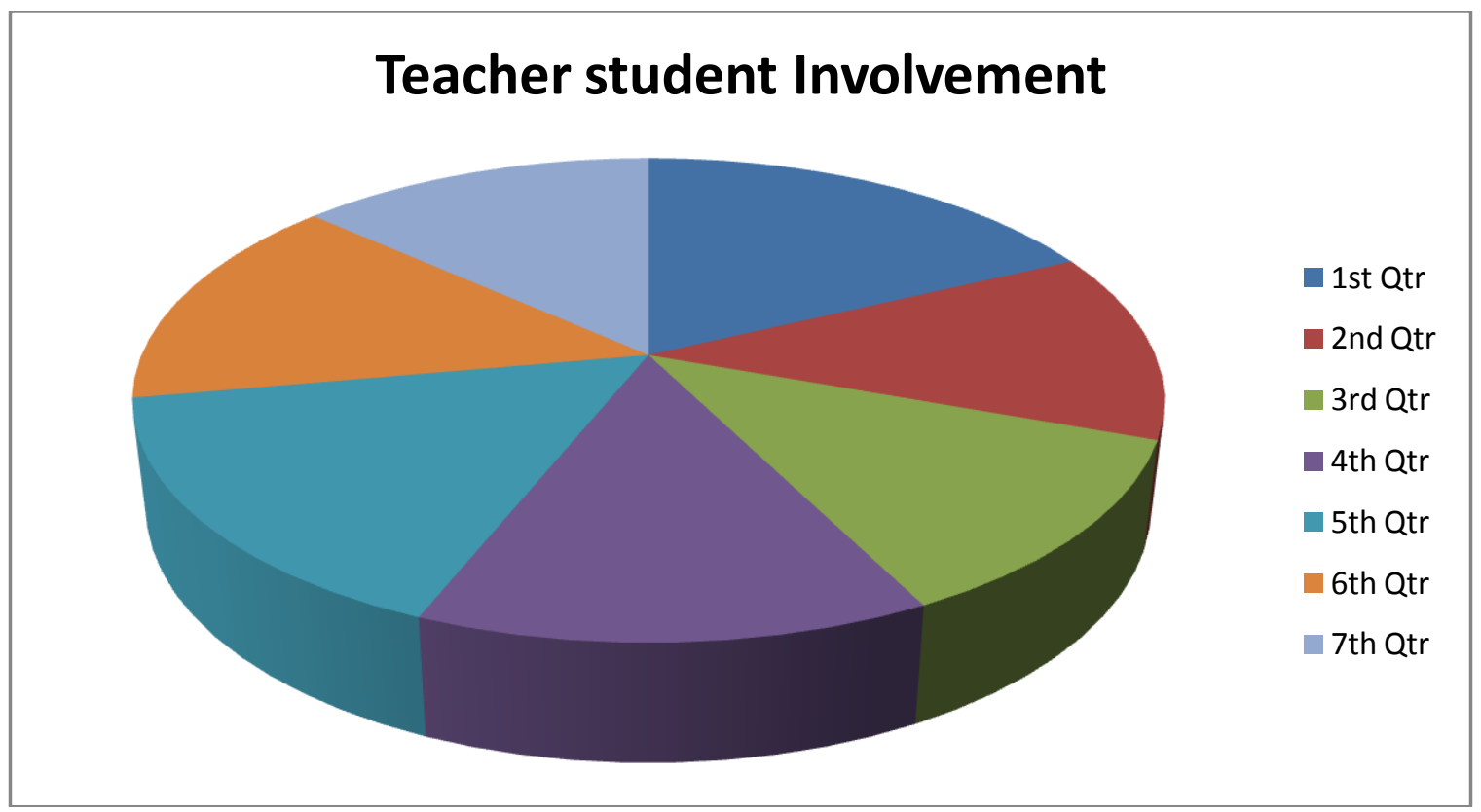

Annex 3:-

Statement \# 3:- Evaluation and Assessment process.

\begin{tabular}{|l|l|l|l|l|}
\hline S.No & Items & Mean & SD & Avg T test \\
\hline 1 & AKU-EB follows E-marking system. & 0.88 & 0.087 & 0.103 \\
\hline 2 & Any other board follows the E-marking as AKU-EB does. & 0.507 & 0.05 & 0.103 \\
& AKU-EB question paper is prepared by trained experts/teachers & 0.86 & 0.085 & 0.103 \\
\cline { 1 - 3 } & $\begin{array}{l}\text { AKU-EB answer sheet e marking is done by the experts in } \\
\text { corresponding subjects. }\end{array}$ & 0.87 & 0.086 & \multirow{2}{*}{0.103} \\
\cline { 1 - 3 } & Board uses modern techniques for announcing results. & 0.87 & 0.086 & 0.103 \\
\cline { 1 - 3 } & AKU-EB uses technology in collecting information. & 0.58 & 0.057 & 0.103 \\
\hline
\end{tabular}

\section{Evaluation and Assesment Process}

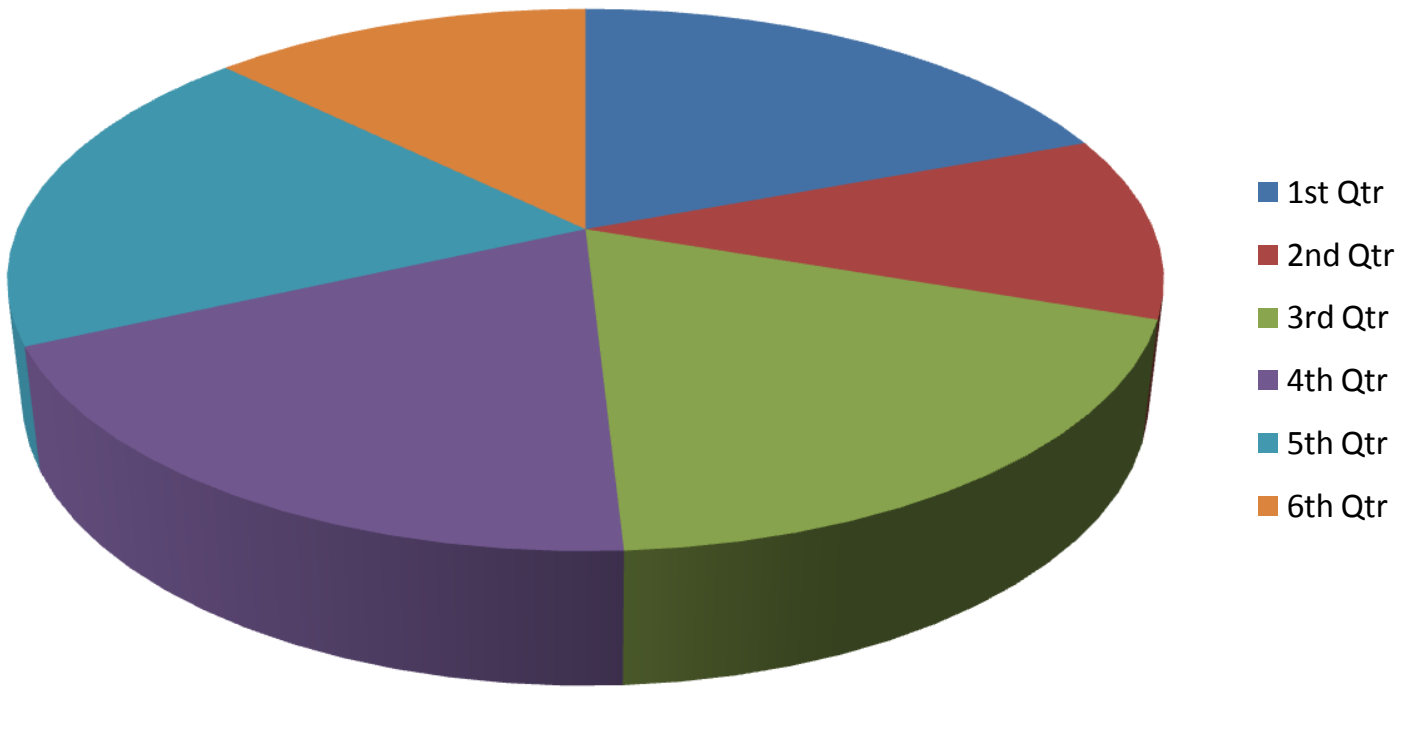




\section{Annex4:-}

Statement \# 4:- Monitoring System:-

\begin{tabular}{|l|l|l|l|l|}
\hline S.No & Items & Mean & SD & Avg T test \\
\hline 1 & AKU-EB monitors the libraries in its affiliated schools. & 0.54 & 0.053 & 0.103 \\
2 & AKU-EB monitors the reading room in its affiliated schools. & 0.51 & 0.050 & 0.103 \\
3 & AKU-EB monitors the internet access in its affiliated schools. & 0.64 & 0.064 & 0.103 \\
4 & AKU-EB monitors school set up. & 0.54 & 0.0535 & 0.103 \\
5 & AKU-EB monitors co curricular activities in schools. & 0.69 & 0.068 & 0.103 \\
6 & AKU-EB maintains the criteria of teacher in the schools to promote & 0.54 & 0.053 & 0.103 \\
7 & quality education. & 0.67 & 0.065 & 0.103 \\
& $\begin{array}{l}\text { AKU-EB has any system to evaluate teaching methodologies in } \\
\text { affiliated schools. }\end{array}$ & & & \\
\hline
\end{tabular}

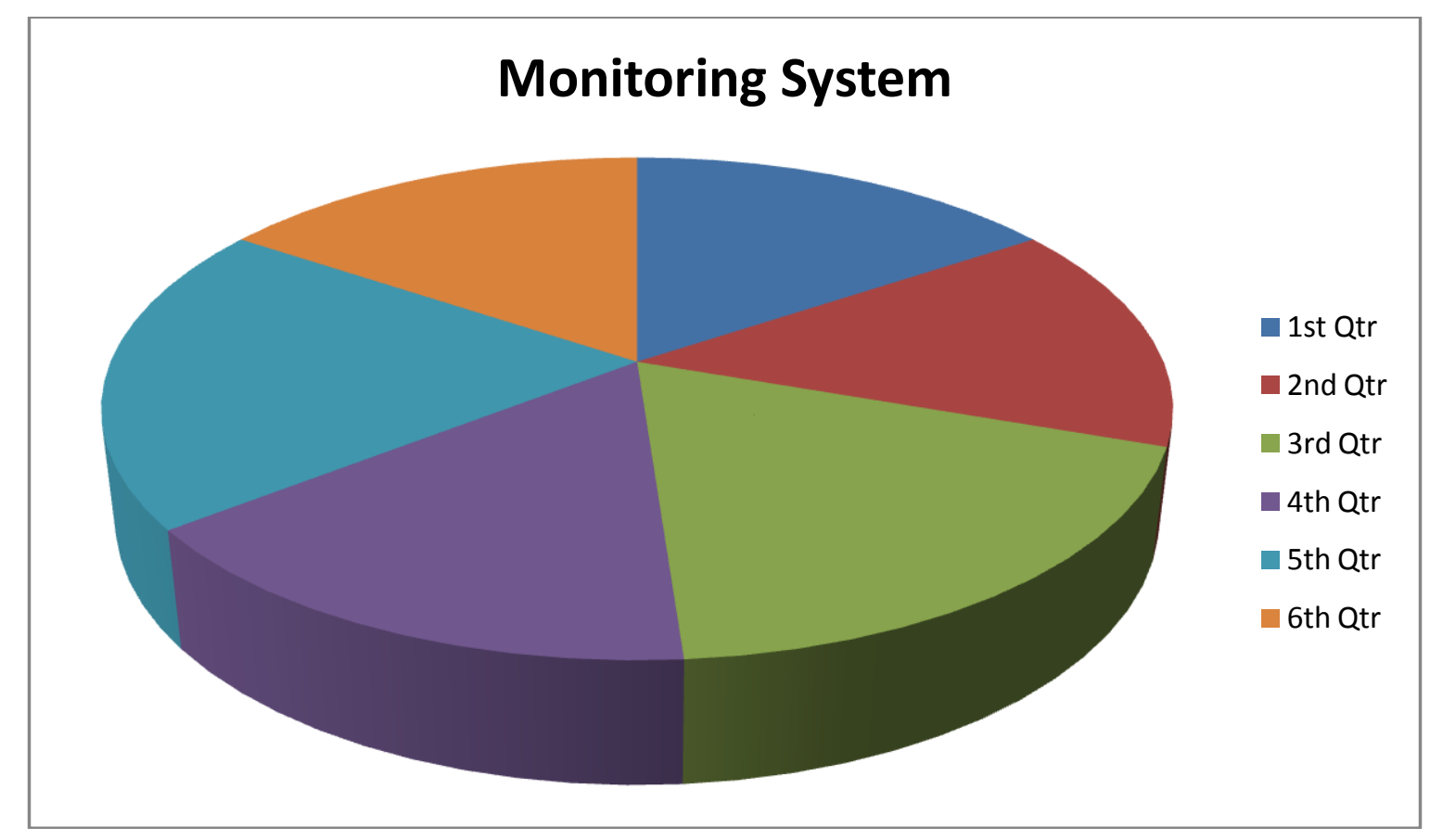

